Research Article

\title{
Internship program: A viewpoint of pre-service teachers of Farhangian University-Shahid Beheshti branch of Tehran
}

Darioush Sharafie a,1,*, Mohamadreza Ghorbani b,2, Amin Dadashzadeh, b,2

a Department of Chemistry, Faculty of Science, Farhangian University, Tarbiat Moallem Ave., Hashemi Rafsanjani Junction,

Farahzadi Blvd. Tehran 1939614464, I.R. of Iran

${ }^{\circ}$ Biology Education, Faculty of Science, Farhangian University, Tarbiat Moallem Ave., Hashemi Rafsanjani Junction,

Farahzadi Blvd. Tehran 1939614464, I.R. of Iran

${ }^{1}$ sharafie@cfu.ac.ir*; ${ }^{2}$ d.sharafie@yahoo.com

${ }^{*}$ Corresponding author

\begin{tabular}{|c|c|}
\hline ARTICLE INFO & ABSTRACT \\
\hline $\begin{array}{l}\text { Article history } \\
\text { Received February 03, } 2019 \\
\text { Revised May 29, 2019 } \\
\text { Accepted June 29, } 2019 \\
\text { Published July 16, } 2019 \\
\text { Keywords } \\
\text { Internship } \\
\text { Farhangian University } \\
\text { Pre-service teacher }\end{array}$ & $\begin{array}{l}\text { Internship has been considered as a crucial program in preparing pre-service teachers } \\
\text { to implement the scientific-practical activities knowledge they have gained. This study } \\
\text { aimed at describing the implementation as well as the function of internship program } \\
\text { based on pre-service teachers' of Farhangian University-Shahid Beheshti branch of } \\
\text { Tehran viewpoint. The statistical population of this study was the student teachers of } \\
\text { Shahid Beheshti Higher Education Center entering the year } 2015 \text { in which the } 119 \\
\text { people of them were selected as the sample. As many as } 31 \text { questions about six main } \\
\text { criteria (the assessment of Farhangian University, internship course lecturers, schools } \\
\text { where the interns went for internship, teachers who guided interns in schools, self- } \\
\text { assessment of internships and the assessment of education department) were } \\
\text { designed and verified by internship professors and then a five-choice questionnaire was } \\
\text { designed based on Likert Scale. The data obtained then analyzed using single sample } \\
\text { t-test. The results obtained from the questionnaire proved that the university, internship } \\
\text { lecturers and guidance teachers did not succeed in fulfilling their tasks. Thus, a good } \\
\text { coordination among university, Department of Education, and schools should be } \\
\text { established. }\end{array}$ \\
\hline
\end{tabular}

Copyright (C) 2019, Sharafie et al This is an open access article under the CC-BY-SA license

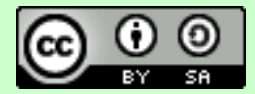

How to cite: Sharafie, D., Ghorbani, M., \& Dadashzadeh, A. (2019). Internship program: A viewpoint of pre-service teachers of Farhangian University-Shahid Beheshti branch of Tehran. JPBI (Jurnal Pendidikan Biologi Indonesia), 5(2), 361-366. doi: https://doi.org/10.22219/jpbi.v5i2.7645

\section{INTRODUCTION}

Teaching can be considered as the art of transferring knowledge, skills, and experiences to learners (students, student teachers). Interm of teaching teacher students, this including general knowledge that enables teacher students to make right decision and to do their teaching optimally. Thus, they can communicate various aspects such as science and culture, religion, language, and politics. To enable the teacher student to do this and improve their competencies from beginner level to professional teachers, teacher students must identify teaching methods and the implementation. The only possible way to cultivate this 
profound understanding is by allowing the student teachers to attend classes accompanied and supervised by professional teacher. As the knowledge and experiences transfer is occurred from professional teacher, the student teachers will learn how to deal with various situations as well as complicated problems which possibly occurred during class sessions. Moreover, the student teachers can modify and develop the practical concepts they obtained from professional teacher with their own creativity. This practical experience can be obtained from internship program. Not only do student teachers gain experiences in observing class activities, but from this program, they also try to implementing the concepts they obtained during their theorical class and sensing to be a real teacher. Therefore, internship is a crucial aspect which determines whether student teachers pass or fail their teacher education program.

Internship refers to a set of activities which prepare student teachers to implement scientific-practical activities with the knowledge they have gained. For this purpose, internship activities must be designed in a way which enables student teachers to gained various experiences and learn different teaching methods as important as learn how to create new teaching methods and how to deal effectively with the problems they face during their internship program. Based on the above important internship aspects, student teachers success in internship program is a prove that they deserve to attend and teach students. Contrarily, they who do not pass this practical course are considered as unqualified teacher. In the other words, they are not allowed to teach students as their lack of competencies (Ball \& Forzani, 2009; Grossman et al., 2009).

In the nineteenth century, interns were sent to schools without any well design for their internship program. At that time, teachers believed that learning is a passive activity which means that it does not challenge student they taught. Thus, the teachers in class did merely deliver the materials by lecturing and supervising to students' homework. As the consequences, the interns who were learning in those kinds of schools imitated the teacher performances they observed. However, some studies showed that internship in leading countries, particularly in science, has undergone many changes over the past decades, this shows that they had a special sensitivity to the implementation of internship program itself (Cuban, 1993).

Internship program will facilitate students teachers to communicate their knowledge and sharpen their skills in teaching. To go further, they also will be more familiar with the real school environment as well as identify the advantages and limitations they will find in their future professional field. Hence, it gives teacher students great confidence and prepares them to attend their future classes as teachers (Grimmett \& Mackinnon, 1992; Schön, 1983).

To be more detail, through internship program, teacher students' learning will be more effective as they get use to with educational technique development. For instance, teacher students can observe directly and integrate their concepts about modeling and problem-solving strategies, practical activities, image and animation uses in the classroom. Thus, they observe and learn the created situations in schools, during teaching and learning process. Moreover, they can make teaching characteristics and features themselves (Cochran-Smith, 2008; Ghousseini \& Sleep, 2011; McDonald, Kazemi, \& Kavanagh, 2013). Studies by Wilson, Floden, and Ferrini-Mundy (2002). indicated that experienced teachers and graduate teacher students believed that the experiences gained during the internship course are the most important components of teacher training (Wilson et al., 2002). In Iran, the process of preparing teacher students to be a skillful teacher is conducted in Farhangian University. The curriculum preparation for undergraduate internship course has played a key role at Farhangian University. This due to its crucial factor in term of the first educational experience for teacher students to learn how to integrate their academic knowledge and theories as well as to sharpen their personal skills altogether in a certain period of time in workplace.

In the new era at Farhangian University, internship has been seriously considered with a new and different approach compared to the previous era. In nowadays proposed program of Farhangian University, internship program has been designed to produce creative teachers based on their learning processes as well as the reflection during the program they conduct. Thus, self-confidence and professional skills must be enacted by interns in order to be able to transfer their knowledge in the classroom. During the internship course, teacher students gain this chance to expand their attitudes and their teaching methods (Giebelhaus \& Bowman, 2002). Moreover, self-efficacy is also the other important gain which must be achieved by teacher students during their education processes. This is crucial aspect to empower their belief that they have ability to do their tasks in educational field as powerful as ability in giving positive effect to their future students' learning performance (Bandura, 1997).

However, some previous studies reported that internship course has contributed problems (Bansal, 2004) and failed to achieve its expected learning outcomes. One of these problems is the irrelevancy of the internship with the curriculum designed. The factual condition at the time was that interns considered that this course is a 
break time (Nyongesa, 2015). Moreover, the process of an internship with new methods has drawbacks which put the results at risk. This research aimed at revealing the unproper points of internship processes among chemistry, biology, and mathematics teacher students who entered Farhangian University-Shahid Beheshti branch in 2015 and enunciating its applications.

\section{METHOD}

The population in this research was teacher students in majors of chemistry, biology and physics of academic year 2015 in Farhangian university-Shahid Beheshti branch. The number population member were 119 teacher students, they were also selected as the sample. The formal and contextual validity of the questionnaire were studied and checked by internship professors and experts of the internship. By considering their comments, the questionnaires were modified. The reliability evaluation of the research was confirmed by using Cronbach's alpha which was calculated using SPSS-22 software. The Cronbach's alpha coefficient (0.89) indicated that the questionnaire was reliable. The questionnaire comprised of 31 questions in which the Likert scale with 5 choices (from high $=5$ to low $=1$ ) were chosen. Score 3 was selected as the average score for theoretical responses. Before presenting the questionnaire, the explanation about this research was given to the teacher students and ensure their awareness about their contribution in research. The questionnaire used consisted of six main criteria (i.e. four questions of Farhangian University assessment, five questions from internship professors, six questions from teacher students' internship schools, seven questions from internship guidance teachers, six questions of internship self-assessment and three questions from education department as the end assessment). Each criterion was in separated section in which the questions were designed and layouted using questionnaire template. After piloting and determining the validity and reliability, the questionnaires were given to the respondents via messenger and the responses were received in the same way. The data obtained were then analyzed using SPSS 22.

\section{RESULTS AND DISCUSSION}

Internship program contribute many positive practical impacts for students. It gives a practical experiences, opens the opportunity for interns to be hired a s full-time job by the institutions they conduct their internship (Zhao \& Liden, 2011), and so forth. Thus, the better the management of this program the more optimum the results achieved. In considering this mater, planning and evaluating are the important processes to be done by the related parties such as schools, students, and stakeholders (institutions where the internships are conducted).

The recent study resulted the average scores of internship evaluation components obtained from respondents involved. Based on Figure 1, it can be seen that most of respondents consider that internship was enjoyable activity in which the mean value was 5 . In contrast, there about only few students who dislike to conduct internship; while the remain respondents (mean value $=3.66$ ) considered that neither was internship a favorable program nor the favorable one.

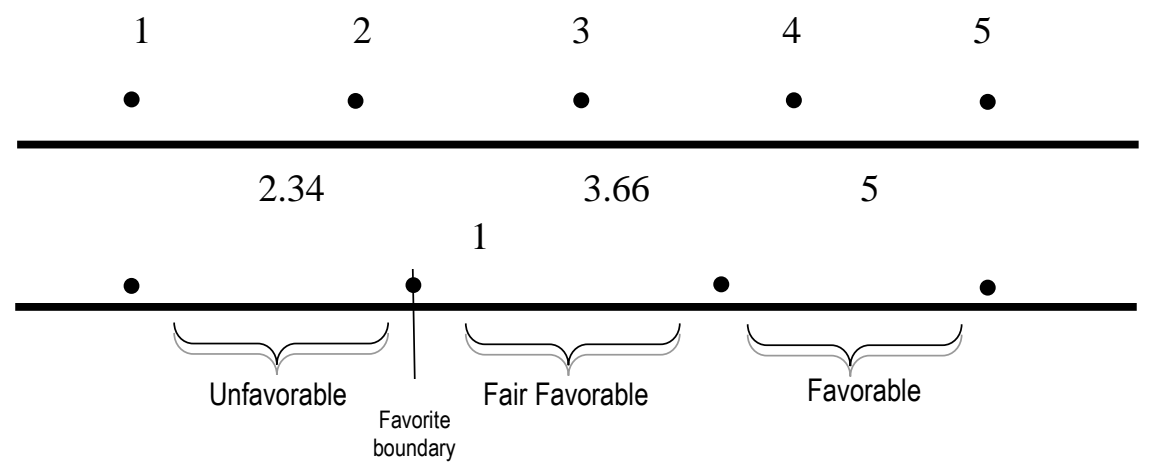

Figure 1. Evaluation Spectrum questions scores in Likert Spectrum

This finding is inline with the previous study conducted by Renganathan, Karim, and Li (2012) which reported that generally, students have a positive perception about internship. There are various reasons undergirding this perception such as the clear description of workplace culture, work organization and how the 
employees do their efforts to achieve their individual as well as institution's goals. By regarding these detail and real conditions themselves, students will be encouraged to reach their employability level. Those experiences will ease them to do self-evaluation and improvement in terms of strengthen their skills and competencies they feel need to be strengthened.

A single-sample t-test was done to analyze the questionnaire results obtained from students responses in which the analysis results are served in Table 1. According to this table, it can be said that, in general, the all components assessed were significantly different compared to the theoretical mean responses $(p=0.0001<$ 0.05 ) and were categorized as fairly favorable. It can be enunciated as below.

The internship students' performance was highest criteria compared to the others, in which the mean value was 3.60. The second highest mean was possessed by "function of schools accepting interns" criteria (3.35). Contrarily, the "function of Farhangian University" criteria got the lowest positive responses from the students (mean value $=2.45$ ), even though it still in fairly favorable rate. Meanwhile, the remain criteria were still under below the theoretical average.

Table 1. The data analysis results of students' responses about the internship components

\begin{tabular}{llllll}
\hline \multicolumn{1}{c}{ Component } & $\mathbf{t}$ & sig & mean & $\begin{array}{l}\text { Compare with } \\
\text { theoretical mean }\end{array}$ & Favorite rate \\
\hline Function of internship students & 14.04 & 0.0001 & 3.60 & Higher than mean & Fairly favorable \\
Function of schools accepting interns & 6.97 & 0.0001 & 3.35 & Higher than mean & Fairly favorable \\
Function of the education department & -2.31 & 0.02 & 2.83 & Lower than mean & Fairly favorable \\
A function of internship professors & -5.11 & 0.0001 & 2.70 & Lower than mean & Fairly favorable \\
A function of internship guide teachers & -8.70 & 0.0001 & 2.48 & Lower than mean & Fairly favorable \\
A function of Farhangian University & -6.67 & 0.0001 & 2.45 & Lower than mean & Fairly favorable \\
$\mathrm{P}=0.05, \mathrm{n}=119$ & & & & & \\
\hline
\end{tabular}

In accordance with the previous data, the single-sample t-test analysis showed the similar results, it can be seen that students believe that internship gives strong impact to their study processes. As the positive responses from many parties, internship programs has been chosen in various fields to give useful practical experiences for their students such as medical (Hadley et al., 2010), education (Liu, Xu, \& Weitz, 2011), tourism (Busby \& Gibson, 2010), economic (Nunley, Pugh, Romero, \& Seals, 2016), pharmacy (Hadley et al., 2010), industry (Renganathan et al., 2012), and so forth.

The role of schools or institutions where students conduct this practical study is the determining factor for their performance. Interns, somehow, expect the chances to deal with the challenges, to enact lesson learns, as well as facilitate career growth. In the other word, job characteristic will effect to the job satisfaction (Busch \& Bush, 1978). Therefore, internship places are recognized as the most determining factor for interns' convenience. The hospitality of the people, the facilities available, the administration mater, the organization and the culture in interns work places are the things that they have to deal with.

The other factor affecting the process of internships are educational institutions that play a considerable role in the dynamic phenomena found in this study. Several documents of Farhangian university including the university statute considered that internship is a special course for teacher students, besides as scientific and practical support for them. Internship has been reported improved communication, self-efficacy, professional competence skills and created a positive attitude toward teaching profession. In fact, Internship is one of the best positions in the field of action which creates opportunities for teacher students to improve their competencies in class and school base (Schmidt et al., 2009).

The results of this study indicated that the institution parties (the both levels: department and university) were not optimum in managing internship. This possibly as the consequences of the improper mindset of the education managers. The lack of the belief that by providing internship, they can assure the next generation quality, somehow, will lead the education managers to underestimating the program. Hence, the education institution must change this improper perception. As the right mindset is formed, the university should be the most helpful party to facilitate their students' in their internship program in term of preparing the all materials they need to complete their internship tasks. One of the helpful facilities can be provided by university is conducting a good coordination about their curriculum to the intern students. Blog can be one of the media can be utilized by university to held a good communication with the interns (Chu, Chan, \& Tiwari, 2012). Students who had well communication about their university curriculum during internship course had better learning in compare with who did not have it (Sørensen, Haugbolle, Herborg, \& Tomsen, 2005). The better the services provided by university, the better the students' perception about their department and university will be. 
One of the most important factors that affect internship or teachers training is the role of the internship professors. In this research, it has been shown that although the average of this criterion is in the relatively favorable range, the mean value gained was still lower than the theoretical average. The lack of professors' knowledge about internship program in branch of Farhangian University was the main factor found in this study. As the results, these professors were not thought mandated or obligated to guide the teacher students, and many of them did not have enough awareness about the university's requirements for internship topics. The observation results (not served in this paper) showed that the presence of internship professors in schools to observe teacher students situation was low.

Based on the above conditions, Farhangian University should improve teacher students skills by making a suitable platform. Moreover, it should provide teacher students a good opportunity to enhance their abilities in teaching with regular and accurate implementation of internship courses as well as providing the most updated resources needed. The university must also employee the professors who have enough information about internship theoretical and practical aspects. This can be done by organizing compulsory courses in the related field for professors.

\section{CONCLUSION}

The survey results obtained in this study showed that the internship at Shahid-Beheshti Higher Education Center was not in unfavorable situation, however, the mean values of the criteria examined were far from the desired status. Teacher student had less satisfaction with the performance of internship professors, guidance teachers, and Farhangian University, even though the performance of internship-accepting schools was better evaluated. The poor professors' presence in schools as considerable as the inadequate knowledge about internship program have led them failed to motivate their interns. The coordination among university, education department and schools were unoptized yet.

\section{ACKNOWLEDGEMENT}

We would like to thank and appreciate to the Farhangian University for financial support so that this study could be conducted and completed.

\section{REFERENCES}

Ball, D. L., \& Forzani, F. M. (2009). The work of teaching and the challenge for teacher education. Journal of Teacher Education, 60(5), 497-511. doi: https://doi.org/10.1177/0022487109348479

Bandura, A. (1997). Self-efficacy: The exercise of control. Worth Publishers. Retrieved from https://books. google.co.id/books/about/Self_Efficacy.html?id=eJ-PN9g_o-EC\&redir_esc=y

Bansal, R. K. (2004). Need for strengthening of internship (rotatory housemanship) training in India. Education for Health, 17(3), 332-338. doi: https://doi.org/10.1080/13576280400002528

Busby, G. D., \& Gibson, P. (2010). Tourism and hospitality internship experiences overseas: A british perspective. Journal of Hospitality, Leisure, Sport and Tourism Education, 9(1), 4-12. doi: https://doi.org /10.3794/johlste.91.244

Busch, P., \& Bush, R. F. (1978). Women contrasted to men in the industrial salesforce: Job satisfaction, values, role clarity, performance, and propensity to leave. Journal of Marketing Research, 15(3), 438. doi: https://doi.org/10.2307/3150592

Chu, S. K. W., Chan, C. K. K., \& Tiwari, A. F. Y. (2012). Using blogs to support learning during internship. Computers and Education, 58(3), 989-1000. doi: https://doi.org/10.1016/j.compedu.2011.08.027

Cochran-Smith, M. (2008). Handbook of research on teacher education: Enduring questions and changing contexts. Retrieved from https://www.amazon.com/Handbook-Research-Teacher-Education-Questions/ dp/0805847774

Cuban, L. (1993). Hoe teacher taught. (D. C. Berliner, J. E. Brophy, T. L. Good, M. Lampert, V. RichardsonKoehler, \& R. Slavin, Eds.) (Second). New York, USA: Teachers College Press. Retrieved from https:// www.amazon.com/How-Teachers-Taught-Constancy-Classrooms/dp/0807732265

Ghousseini, H., \& Sleep, L. (2011). Making practice studyable. ZDM - International Journal on Mathematics Education, 43(1), 147-160. doi: https://doi.org/10.1007/s11858-010-0280-7

Giebelhaus, C. R., \& Bowman, C. L. (2002). Teaching mentors: Is it worth the effort? Journal of Educational Research, 95(4), 246-254. doi: https://doi.org/10.1080/00220670209596597 
Grimmett, P. P., \& Mackinnon, A. M. (1992). Chapter 9: Craft Knowledge and the Education of Teachers. Review of Research in Education, 18(1), 385-456. doi: https://doi.org/10.3102/0091732X018001385

Grossman, P., Compton, C., Igra, D., Ronfeldt, M., Shahan, E., \& Williamson, P. W. (2009). Theaching practice: A cross-professional perspective. Teachers College Record, 111(9), 2055-2100. Retrieved from https://tedd.org/wp-content/uploads/2014/03/Grossman-et-al-Teaching-Practice-A-Cross-Professio nal-Perspective-copy.pdf

Hadley, J., Kulier, R., Zamora, J., Coppus, S. F. P. J., Weinbrenner, S., Meyerrose, B., ... Khan, K. S. (2010). Effectiveness of an e-learning course in evidence-based medicine for foundation (internship) training. Journal of the Royal Society of Medicine, 103(7), 288-294. doi: https://doi.org/10.1258/jrsm.2010. 100036

Liu, Y., Xu, J., \& Weitz, B. (2011). The role of emotional expression and mentoring in internship learning. Academy of Management Learning and Education, 10(1), 94-110. doi: https://doi.org/10.5465/amle. 10.1.zqr94

McDonald, M., Kazemi, E., \& Kavanagh, S. S. (2013). Core practices and pedagogies of teacher education: A call for a common language and collective activity. Journal of Teacher Education, 64(5), 378-386. doi: https://doi.org/10.1177/0022487113493807

Nunley, J. M., Pugh, A., Romero, N., \& Seals, R. A. (2016). College major, internship experience, and employment opportunities: Estimates from a résumé audit. Labour Economics, 38, 37-46. doi: https:// doi.org/10.1016/j.labeco.2015.11.002

Nyongesa, K. W. (2015). A teachers perspective on the challenges in the delivery of content and performance in biology: A case of Bungoma District, Kenya. Kabarak Journal of Research \& Innovation, 3(2), 23-42. Retrieved from http://eserver.kabarak.ac.ke:8082/ojs/index.php/journal1/article/view/86

Renganathan, S., Karim, Z. A. B. A., \& Li, C. S. (2012). Students' perception of industrial internship programme. Education and Training, 54(2-3), 180-191. doi: https://doi.org/10.1108/004009112112102 88

Schmidt, D. A., Baran, E., Thompson, A. D., Mishra, P., Koehler, M. J., \& Shin, T. S. (2009). Technological Pedagogical Content Knowledge (TPACK): The development and validation of an assessment instrument for preservice teachers. Journal of Research on Technology in Education, 42(2), 123-149. doi: https://doi.org/10.1080/15391523.2009.10782544

Schön, D. A. (1983). The Reflection of Practicioner. United States of America: Basic Books.Inc. Retrieved from https://www.amazon.co.uk/Reflective-Practitioner-Professionals-Think-Action/dp/0465068782

Sørensen, E. W., Haugbolle, L. S., Herborg, H., \& Tomsen, D. V. (2005). Improving situated learning in pharmacy internship. Pharmacy Education, O(0), 1-11. doi: https://doi.org/10.1080/15602210500319483

Wilson, S. M., Floden, R. E., \& Ferrini-Mundy, J. (2002). Teacher preparation research: An insider's view from the outside. Journal of Teacher Education, 53(3), 190-204. doi: https://doi.org/10.1177/002248710205 3003002

Zhao, H., \& Liden, R. C. (2011). Internship: A Recruitment and Selection Perspective. Journal of Applied Psychology, 96(1), 221-229. doi: https://doi.org/10.1037/a0021295 